\title{
VALORES ORGANIZACIONAIS EM \\ INSTITUIÇÕES PÚBLICAS BRASILEIRAS: \\ PERCEPÇÕES DOS SERVIDORES EM \\ DIFERENTES POSIÇÕES HIERÁRQUICAS E \\ TIPOS DE ENTIDADE DA ADMINISTRAÇÃO
}

INDIRETA

\begin{abstract}
VIRGINIIA DONIZETE DE CARVALHO
Doutora em Psicologia Social pela Faculdade de Ciências Humanas, Letras e Artes da Universidade Federal do Rio Grande do Norte (UFRN).

Professora do Instituto de Ciências Sociais Aplicadas da Universidade Federal de Alfenas (Unifal). Rua Celina Ferreira Ottoni, 4.000, Padre Vitor, Varginha - MG - Brasil - CEP 37048-395
\end{abstract}

E-mail: virginiadcarvalho@gmail.com

THAIS ALUXE DE OLIVEIRA

Graduanda do Bacharelado Interdisciplinar em Ciência e Economia do Instituto de Ciências Sociais Aplicadas da Universidade Federal de Alfenas (Unifal).

Rua Celina Ferreira Ottoni, 4.000, Padre Vitor, Varginha - MG - Brasil - CEP 37048-395

E-mail: thaisaluxe@uol.com.br

\section{DANIELE CRISTHIANE DA SILVA}

Graduanda em Economia com ênfase em Controladoria do Instituto de Ciências Sociais Aplicadas da Universidade Federal de Alfenas (Unifal). Rua Celina Ferreira Ottoni, 4.000, Padre Vitor, Varginha - MG - Brasil - CEP 37048-395

E-mail: daniele_1006@hotmail.com 


\section{RESUMO}

O estudo teve como objetivo identificar as percepções de servidores acerca dos valores organizacionais em instituições públicas da administração indireta federal, visando observar a ocorrência de variações segundo a posição hierárquica desses profissionais e o tipo de entidade analisada. Com esse propósito, focalizaram-se quatro instituições, utilizando uma amostra de $\mathrm{I} 28$ servidores, aos quais foi aplicado o Inventário de Valores Organizacionais (TAMAYO; MENDES; PAZ, 2000). Os resultados apontaram que, não obstante a concordância entre gestores e subordinados sobre o conjunto de valores que constituem as prioridades axiológicas das instituições analisadas, os primeiros julgam que são mais relevantes os valores de autonomia, e os segundos, os de hierarquia. Quanto às prioridades axiológicas nas diferentes entidades, as percepções apontam alguns elementos de diferenciação representados pela importância dos valores de autonomia para a autarquia e a fundação pública e dos de domínio para a empresa pública e a sociedade de economia mista. Prevalece, entretanto, a similaridade na hierarquização de valores nessas instituições, com maior ênfase na hierarquia e no conservadorismo, demonstrando que, a despeito das iniciativas implementadas a partir da reforma gerencial nos anos I990, essas instituições seguem caracterizadas principalmente por princípios relacionados à conservação de sua estrutura, costumes, normas e tradições, além de expressarem foco na autoridade, na obediência e no poder social. As implicações, limitações e contribuições do estudo são discutidas, com sugestões para pesquisas futuras.

\section{PALAVRAS-CHAVE}

Valores organizacionais; Percepção de valores; Servidores públicos; Instituições públicas; Administração indireta. 


\section{INTRODUÇ ÃO}

As transformações vivenciadas no campo da gestão pública no Brasil, nas últimas décadas, vêm sendo tema de debate. Em um contexto de redemocratização do país, identifica-se uma busca por revitalizar a ação do Estado, tanto em termos de melhoria no desempenho da prestação do serviço público quanto da criação de novos padrões de relação com a sociedade (PAULA, 2005; MOTTA, 2007; ANDION, 20I2). Observa-se que tais transformações, entretanto, têm sido permeadas por dificuldades e desafios, dentre estes, a manutenção de muitas das características tradicionais da gestão pública, a despeito da introdução de novas rotinas e expectativas de modernização (MOTTA, 2007).

Silva e Fadul (2010) ponderam que a cultura organizacional pode assumir papel relevante para a compreensão do desempenho nas organizações públicas, sobretudo quando se consideram as intervenções nas dimensões institucional-legal, cultural e de gestão propostas a partir da reforma do Estado de I995, também conhecida como reforma gerencial. Conforme salientam esses autores, a dimensão cultural, em especial, recebe destaque no Plano Diretor de Reforma do Aparelho do Estado, à medida que é apontada como elemento essencial para o sucesso da proposta de redefinição de espaços e papéis do Estado e a consequente transformação na gestão das organizações públicas.

Dada, entretanto, a complexidade da cultura como construto, os valores que constituem seu componente central (SCHWARTZ; BILSKY, I987; TAMAYO; SCHWARTZ; I993; BORGES et al., 2002) têm sido crescentemente abordados como variável de estudo. Quando aplicados ao âmbito das organizações, os valores podem ser definidos como princípios ou crenças, organizados hierarquicamente, relativos a condutas ou metas desejáveis, que orientam a vida em grupo, estando a serviço de interesses individuais, coletivos ou ambos (TAMAYO; BORGES, 2006). Com sua origem na interação social, são construídos em decorrência das necessidades do trabalho a ser realizado para orientar as relações internas e externas, atuando como elementos definidores de uma organização e expressando a sua singularidade e especificidade (MACÊDO et al., 2005; HASSAN, 2007).

Tomando-se o caso das instituições públicas, registra-se que várias pesquisas abordando os valores nesse contexto têm sido desenvolvidas (MENDES; TAMAYO, 200I; BORGES et al., 2002; TAMAYO, 2005; BORGES; ARGOLO; BAKER, 2006; NEIVA; PAZ, 2007; entre outras), algumas delas tecendo comparações entre organizações públicas e privadas (MACÊDO et al., 2005; PORTO; TAMAYO, 2005; ANDRADE; ESTIVALETE, 20I0). Observa-se, contudo, que nenhum dos estudos levantados discute a identificação dos valores organiza- 
cionais considerando as implicações do contexto pós-reforma do Estado de I995, embora a maioria deles tenha sido desenvolvida a partir dos anos 2000. Não se identificou também a abordagem dos valores, de forma comparativa, entre os diferentes órgãos da administração indireta, a despeito de sua criação ter sido fundamentada por pressupostos de descentralização, profundamente alinhados aos ideais que viriam a ser defendidos posteriormente na reforma gerencial. Ademais, as instituições da administração indireta representam uma parcela significativa da máquina pública brasileira, como apontam os dados do Boletim Estatístico de Pessoal do Ministério do Planejamento, Orçamento e Gestão (20I2), segundo o qual, em 20II, os servidores federais nelas lotados constituíam 33,4\% do total geral de ativos da união, sendo 245.569 deles atuantes em autarquias, 9I.IO7 em fundações públicas, 25.398 em empresas públicas e I5.682 em sociedades de economia mista.

Buscando preencher essa lacuna, o presente estudo teve como objetivo central identificar a percepção dos servidores acerca dos valores organizacionais que orientam a gestão nas instituições públicas da administração indireta, visando observar a ocorrência de variações nessa percepção de acordo com a posição hierárquica e o tipo de entidade analisada. Com esse propósito, focalizou quatro instituições, que representam as diferentes figuras da administração indireta federal, as quais exercem atividades na região sul de Minas Gerais, com vistas a verificar se os valores organizacionais identificados se mostrariam compatíveis com os pressupostos da reforma gerencial, se gestores e subordinados compartilhariam a visão acerca dos valores organizacionais praticados e em que medida a hierarquização de tais princípios se distinguiria conforme o tipo de entidade analisada.

Partindo do exposto, o artigo encontra-se estruturado de modo a apresentar inicialmente uma breve abordagem do contexto de atuação das instituições públicas da administração indireta federal e uma revisão de literatura sobre os valores organizacionais, além da descrição dos procedimentos metodológicos adotados na condução do estudo e da discussão dos resultados obtidos. Ao final, são tecidas considerações acerca dos principais achados do estudo e de suas implicações, destacando-se as contribuições e limitações desta pesquisa.

\section{O CENÁRIO dAS INSTITUIÇÕES PÚBLICAS DA ADMINISTRAÇÃO INDIRETA NO BRASIL}

Tendo em vista a proposta do artigo, torna-se relevante uma contextualização acerca da organização administrativa do Brasil, caracterizando as instituições 
da administração indireta, bem como buscando compreender o cenário em que se inserem, dado o processo de mudança vivenciado a partir da implantação do chamado modelo gerencial na administração pública, cujo entendimento permitirá situar as orientações que têm pautado a gestão nesses órgãos.

A estrutura administrativa do Estado brasileiro, a partir do Decreto-Lei $n^{\circ} 200$ de i967, passou a ser designada em termos de administração direta e indireta. Tal medida representou a descentralização de algumas funções que eram diretamente executadas pelo Estado para outras entidades, de modo a obter maior agilidade, eficiência e flexibilidade de desempenho. Assim, a administração direta foi composta pelos órgãos internos do Estado, e a administração indireta, por pessoas jurídicas, organizadas em quatro categorias: autarquias, empresas públicas, sociedades de economia mista e fundações públicas (CARVALHO FILHO, 2009; BRESSER PEREIRA, I998).

Dentre essas, apenas as autarquias se configuram como pessoas jurídicas de direito público, sendo as demais dotadas de personalidade jurídica de direito privado. Ao passo que as autarquias se caracterizam por desempenhar funções próprias e típicas do Estado, as empresas públicas e sociedades de economia mista têm em comum o fato de exercerem atividades gerais de caráter econômico, diferenciando-se essas últimas por assumirem a forma de sociedades anônimas, com controle acionário pertencente ao Poder Público. As fundações públicas, por sua vez, desenvolvem atividades que não exijam execução por órgãos de direito público, possuindo um patrimônio personalizado, dirigido a um fim específico, que normalmente se trata do desempenho de atividades do Estado na ordem social (por exemplo, educação, trabalhos assistenciais, culturais e de pesquisa) (CARVALHO FILHO, 2009). Bandeira de Mello (2008, p. I85) salienta, todavia, o erro presente na afirmação normativa de que as fundações públicas sejam de direito privado, considerando que elas, de fato, são "pura e simplesmente autarquias às quais foi dada a designação correspondente à base estrutural que têm" (base fundacional), uma vez que se submetem, na prática, às limitações e aos controles próprios das pessoas de direito público.

De acordo com Bresser Pereira (I998, p. II), o Decreto-Lei n² 200 de I967 se constituiu como "uma primeira tentativa de reforma gerencial da administração pública brasileira", a qual, ainda não tendo atingido plenamente os objetivos propostos, enfatizou a "descentralização mediante a autonomia da administração indireta, a partir do pressuposto da rigidez da administração direta e da maior eficiência da administração descentralizada". Considerando, conjuntamente, a introdução das inovações trazidas pelo Decreto-Lei $n^{\circ} 200$ e a descentralização político-institucional, propiciada a partir da Constituição de I988, a qual favoreceu que se voltasse a discutir a relação entre Estado e sociedade, Silva e Fadul (20I0) entendem que tais mudanças teriam provocado grandes impactos na 
cultura das organizações públicas. Comentam, ainda, que, com a implantação da reforma de I995, o próprio processo de criação e manutenção de uma cultura gerencial passava a ser visto como fundamental para impulsionar a mudança pretendida (SILVA; FADUL, 20IO).

Em linhas gerais, tal mudança, pautada por objetivos de maior eficiência econômica do Estado e consubstanciada no Plano Diretor da Reforma do Estado, elaborado no âmbito do Ministério da Administração Federal e Reforma do Estado, consistia numa reconfiguração das estruturas estatais, tendo como base a substituição do modelo burocrático de administração pública por um modelo gerencial, o qual propunha a transposição de ferramentas de gestão do setor privado para o público (MATIAS-PEREIRA, 2008). O entendimento era de que uma administração eficiente do setor público seria alcançada como decorrência da adoção de instrumentos gerenciais (assumindo-se a validade universal das práticas de gestão privada), uma vez que os problemas existentes eram atribuídos à inadequação de estruturas, procedimentos e inabilidades dos servidores, não se questionando fundamentalmente a administração pública, mas sua ineficiência ou iniquidade (MOTTA, 2007).

Inspirada no gerencialismo britânico e influenciada pelos princípios da Nova Administração Pública, a reforma visou inaugurar um novo padrão de gestão pública, calcado na busca por maior flexibilidade, ênfase em resultados, foco no cliente e controle social. Autores comentam, todavia, que, vários anos depois, as metas não foram alcançadas conforme se desenhara, com muitos elementos de continuidade se mostrando presentes (MATIAS-PEREIRA, 2008), especialmente no tocante às características tradicionais da administração pública brasileira, que não foram superadas (MOTTA, 2007).

Discute-se também a noção de substituição do modelo burocrático de administração pública pelo gerencial, proposta na reforma. Conforme Martins (I997), nunca se logrou concretizar no Brasil um modelo de burocracia pública, mas uma combinação burocrático-patrimonialista, marcada pela dissociação entre política e administração. Nessa linha de raciocínio e defendendo a necessidade de realização efetiva de alguns dos princípios da burocracia, Azevedo e Loureiro (2003) discutem que a defesa de uma "substituição" do modelo burocrático não é adequada, uma vez que a flexibilização de processos e procedimentos não impõe um abandono de seus princípios.

Inserindo-se nesse debate, Abrúcio (2007) também entende que um dos erros de diagnóstico da reforma foi estabelecer uma oposição entre a administração burocrática e a gerencial. Segundo o autor, tratou-se de uma "visão etapista" que tanto produziu atritos desnecessários com setores da burocracia estratégica, quanto conduziu à interpretação de que um modelo se seguia ao outro, em substituição, quando o que ocorreu de fato foi um processo no qual os aspectos de 
ambos foram incorporados. Observa, inclusive, que, embora a ideia de substituição estivesse sendo defendida no Plano Diretor da Reforma do Estado, “a maior mudança realizada foi, paradoxalmente, a continuação e o aperfeiçoamento da civil service reform" (ABRÚCIO, 2007, p. 7I). Não se detendo unicamente nos problemas e dificuldades do que denomina "reforma Bresser", elenca também alguns de seus avanços e salienta que suas ideias tiveram grande difusão pelo país, repercutindo, ainda, nas ações de vários governos subnacionais e em inovações governamentais nos últimos anos.

A esse respeito cumpre refletir em que medida tais ideias estão sendo aceitas e incorporadas no cotidiano das organizações públicas, especialmente aquelas da administração indireta, que são fruto de um processo de descentralização que visou justamente à obtenção de maior agilidade, eficiência e flexibilidade de desempenho na prestação de serviços públicos. Como lembra Motta (2007), a administração pública e a cultura tradicional se encontram fortemente interligadas e não será apenas por meio de reformas administrativas que alguns aspectos orientadores da ação nas diferentes instâncias de governo serão removidos ou modificados. Assim, discute que o patrimonialismo e o personalismo, a despeito dos progressos em termos de modernização institucional, continuam presentes e orientando as práticas de manutenção das coalizões de poder e defesa de objetivos de grupos preferenciais. Embora a análise realizada pelo autor se encontre ancorada predominantemente em exemplos relacionados à administração direta e focalizando aspectos da cultura brasileira, cumpre refletir acerca da orientação cultural prevalecente nas instituições da administração indireta, uma vez que a cultura organizacional guarda estreita relação com a cultura nacional. Nesse sentido, o estudo dos valores organizacionais se apresenta como uma alternativa que pode se mostrar relevante para a compreensão dessa realidade.

\section{OS ESTUDOS SOBRE VALORES ORGANIZACIONAIS}

Nas últimas décadas, tem se observado um crescente interesse no estudo dos valores, o qual se encontra, em grande parte, relacionado ao reconhecimento do papel fundamental que desempenham para o entendimento da cultura. Podendo ser definidos, em linhas gerais, como concepções socialmente compartilhadas sobre o que é bom, correto e desejável (KNAFO; ROCCAS; SAGIV, 20II), os valores são ordenados por sua importância relativa a outros para formar uma hierarquia. Com base nesta, torna-se possível comparar indivíduos, grupos sociais e culturas, não somente em relação a cada um dos valores, mas, particularmente, em relação às prioridades que a eles são dadas (TAMAYO, 2007b). 
Por operarem em múltiplos níveis, os valores, quando usados para caracterizar as sociedades como um todo, representando os critérios comuns que se tornaram úteis na hora de solucionar os problemas da coletividade, são situados no plano cultural. Ao se considerar o plano individual, caracterizam as prioridades que orientam as pessoas, "as bases motivacionais nas quais os valores se apóiam e que são usadas para explicar as diferenças entre os indivíduos" (ROS, 2006 , p. 36), as quais costumam estar relacionadas às decisões tomadas e atitudes manifestadas, encontrando-se na raiz de muitos conflitos vivenciados.

Abordando esses dois níveis de análise, Schwartz (I994a, I999) desenvolveu duas tipologias para o estudo dos valores: uma teoria de valores pessoais e uma teoria de valores culturais. Knafo, Roccas e Sagiv (20II) comentam que são as únicas dentre as teorias transculturais de valores a especificarem a estrutura das dimensões valorativas em termos de conflito e compatibilidade. Assim, a estrutura da teoria de valores culturais, por exemplo, identificou seis tipos de valores que foram representados segundo dimensões bipolares, assim denominadas: conservadorismo e autonomia (intelectual e afetiva); hierarquia e igualitarismo; harmonia e domínio.

Os valores de conservadorismo, os quais enfatizam a manutenção do status quo e da propriedade e a restrição de ações que possam romper com a ordem tradicional, opõem-se aos de autonomia intelectual e afetiva que enfatizam, respectivamente, a promoção e proteção de ideias e direitos individuais independentes e de experiências afetivas positivas. Os valores de hierarquia, os quais envolvem a legitimação da alocação hierárquica de papéis e recursos, encontram-se em oposição aos de igualitarismo, que se referem à transcendência de interesses egoístas em favor do comprometimento voluntário com a promoção do bem-estar alheio. Os valores de harmonia, por sua vez, abordam a ênfase num ajustamento harmonioso ao ambiente e à natureza, sendo opostos aos de domínio, que priorizam o avanço por meio da assertividade, mudança e domínio do ambiente natural e social (SCHWARTZ; ROS, I995; SCHWARTZ, I999). Essa relação de oposição entre os polos de cada uma das três dimensões do modelo significa que a ênfase em um tipo de valor é provável de ser acompanhada da rejeição de outro.

Quanto às relações de compatibilidade, tem-se que os valores de hierarquia e conservadorismo tendem a se relacionar positivamente, pois a legitimidade de uma alocação hierárquica fixa de papéis e recursos tanto corrobora valores de manutenção do status quo quanto é corroborada por eles. Igualitarismo e autonomia (principalmente a intelectual) podem se compatibilizar, dado que o entendimento do indivíduo como ser autônomo que carrega suas responsabilidades para com a sociedade é importante para se aceitar a natureza contratual das relações humanas implícitas no igualitarismo. A relação positiva entre os valores de 
domínio e autonomia pode ocorrer por dividirem a ênfase em atividades estimulantes. Entretanto, se esses interesses forem mais determinados pela coletividade do que pelo indivíduo, haverá uma possível conexão dos valores de domínio com os de conservadorismo. Os valores de domínio podem também se mostrar compatíveis com os de hierarquia, à medida que a assertividade excessiva pode levar a uma distribuição desigual de papéis e recursos, que tende a ser justificada em uma sociedade em que diferenças hierárquicas são vistas como legítimas. Ainda, os valores de harmonia se mostram relacionados aos de conservadorismo quando dividem a ênfase na resistência às mudanças, e aos de igualitarismo, quando compartilham a relevância dada às relações cooperativas (SCHWARTZ; ROS, I995; SCHWARTZ, I999).

Comumente aplicada para conhecer e comparar os valores entre diferentes sociedades ou nações, a teoria de valores culturais de Schwartz (I999) também tem sido adaptada para outros contextos, como o das organizações. A possibilidade dessa adaptação é abordada por Tamayo, Mendes e Paz (2000) quando refletem que a organização, por se constituir em uma coletividade, defronta-se com os mesmos problemas fundamentais de qualquer sociedade. Além disso, um sistema de valores pode estar estruturado em termos de aspectos gerais ou associado a contextos específicos (PORTO; TAMAYO, 2003). No caso das organizações, ao escolherem seus valores, bem como a prioridade dada a cada um deles, é comum que se inspirem nos valores da sociedade e dos seus membros, principalmente os fundadores e aqueles com maior poder de influência (TAMAYO, 2007a, 2008).

De acordo com Fernandes e Zanelli (2006, p. 56), pode-se afirmar que "é através da experiência coletiva que os membros das organizações encontram respostas para as questões do cotidiano da empresa, pois são os valores e crenças compartilhados que definem seu modo de pensar e agir". Esses valores compartilhados, como componentes centrais da cultura organizacional (BORGES et al., 2002; MOTTA; VASCONCELOS, 2006), tendem a se vincular, de forma direta e indireta, aos aspectos de contato intergrupal, cooperação, orientação política, uso de regras de justiça e solução de conflitos, entre outros (ROS, 2006).

Cumpre enfatizar os componentes cognitivo e motivacional presentes no conceito de valores organizacionais. Estes facilitam compreender que os valores são crenças enfatizadas, relativas a várias dimensões da vida organizacional e que funcionam como padrões cognitivos para o julgamento e a justificação do comportamento de si e dos outros (aspecto cognitivo). A importância a eles atribuída pode determinar a quantidade de esforço que os membros da organização investem na emissão de determinados comportamentos, persistindo na execução destes, de forma que expressam interesses tanto do indivíduo como da coletividade (aspecto motivacional) (TAMAYO; GONDIM, I996; TAMAYO, I999). 
Visando à identificação dos valores que orientam as organizações, uma das estratégias que têm sido adotadas consiste em avaliá-los a partir de documentos oficiais, tais como relatórios anuais, estatutos e revistas internas, e selecionar aqueles mais relevantes no discurso oficial. Por meio dessa estratégia, é possível acessar os valores organizacionais formais. Considerando, contudo, que estes nem sempre se realizam conforme preconizado nos documentos oficiais, outra abordagem proposta utiliza a percepção dos trabalhadores para avaliar os valores organizacionais e a sua hierarquia, utilizando-se, para isso, tanto de entrevistas quanto da aplicação de questionários (TAMAYO, 2008).

Um aspecto que cumpre salientar diz respeito ao fato de que, sendo a percepção dos empregados acerca das prioridades axiológicas organizacionais uma operação cognitiva que conduz ao desenvolvimento de uma representação mental da organização, o comportamento e as explicações das rotinas por parte desses empregados serão determinados pela percepção que têm dos valores organizacionais praticados. Dessa forma, a análise de tal percepção fornece indícios sobre a forma como os objetivos gerais da corporação são captados por seus membros, já que "modelos mentais diferentes provocam, inevitavelmente, percepções diferentes da empresa, do comportamento organizacional e das tarefas a serem executadas" (TAMAYO; MENDES; PAZ, 2000, p. 296).

Partindo dessa concepção, alguns esforços têm sido envidados no intuito de prover questionários que se constituam como instrumentos confiáveis de avaliação dos valores organizacionais. Cumpre destacar a significativa contribuição de Tamayo (2007a) a essa empreitada, dado o número de modelos e escalas que construiu e validou para o estudo dos valores no Brasil. Dentre estes, o Inventário de Valores Organizacionais (IVO), elaborado em parceria com duas colaboradoras (TAMAYO; MENDES; PAZ, 2000), pressupõe a distribuição dos valores organizacionais nas três dimensões bipolares, propostas por Schwartz (I994b) e anteriormente referidas. Aplicados ao âmbito das organizações, os polos axiológicos daquele modelo são utilizadas com os seguintes propósitos:

O pólo autonomia avalia a tendência da organização a perceber o empregado como sendo uma entidade autônoma, habilitada para perseguir os seus próprios interesses e fixar as suas metas em harmonia com as metas e normas da organização. [...] O pólo conservadorismo avalia o quanto a organização valoriza a necessidade de conservação de usos, costumes e estruturas de poder já existentes promovendo a manutenção do status quo e da interdição de comportamentos que possam perturbar as normas e as tradições da empresa. O pólo hierarquia avalia a valorização por parte da organização da autoridade, do poder social, da influência, da fiscalização e da supervisão. [...] O pólo igualitarismo avalia a preocupação 
da empresa com o bem-estar dos outros, da organização em geral, a existência de poucos níveis de autoridade e a opção por um gerenciamento de tipo participativo. [...] O pólo domínio avalia a vontade de afirmação assertiva da empresa através do domínio dos recursos materiais, do mercado, da tecnologia e do conhecimento na área específica de atuação. O pólo harmonia avalia o acomodamento harmônico da empresa com o seu meio ambiente, respeitando a natureza e as empresas concorrentes (TAMAYO, 2008, p. 313).

De acordo com Tamayo, Mendes e Paz (2000, p. 296), durante o processo de construção do IVO, observou-se que, embora as três dimensões propostas tenham sido encontradas, a oposição entre os diferentes polos axiológicos só foi confirmada para os valores de hierarquia versus igualitarismo. Quanto às demais dimensões, constatou-se que os valores a elas relacionados não se mostraram conflituosos no âmbito das organizações. Para os autores, trata-se, possivelmente, de uma especificidade da cultura brasileira, que se reflete nas organizações, uma vez que Schwartz (I999) já havia observado em estudo realizado junto a 49 países que, no Brasil, as relações de oposição entre os polos das três dimensões são praticamente inexistentes, o que denota uma possibilidade de convivência ou coexistência pacífica de elementos culturais antagônicos.

Pouco depois de sua publicação, o IVO se difundiu na literatura e vem sendo utilizado em vários estudos (MENDES; TAMAYO, 200I; BORGES et al., 2002; MACÊDO et al., 2005; BORGES; ARGOLO; BAKER, 2006; PORTO; TAMAYO, 2005; FERNANDES; FERREIRA, 2009; FREIRE, 2009; entre outros). Mendes e Tamayo (200I), por exemplo, utilizaram o IVO para estudar a relação ente os valores organizacionais e a vivência de prazer e sofrimento no trabalho entre servidores de uma empresa pública de abastecimento e saneamento; Borges et al. (2002) o empregaram para verificar a relação dos valores organizacionais com a síndrome de burnout junto aos servidores em três hospitais universitários; Macêdo et al. (2005) o aplicaram para analisar o impacto que as organizações em diferentes setores de atividade econômica teriam na percepção dos valores organizacionais praticados; Borges, Argolo e Baker (2006), na replicação de estudo anterior sobre a relação entre valores organizacionais e síndrome de burnout; Porto e Tamayo (2005), para o estudo da relação entre valores organizacionais e comportamento de civismo nas organizações; Fernandes e Ferreira (2009), para investigar o impacto dos valores pessoais e organizacionais no comprometimento organizacional; e Freire (2009), para analisar a relação entre os valores organizacionais expressos pela alta administração e pelos demais trabalhadores em uma empresa do setor de serviços terceirizáveis. 
Considerando-se a fundamentação do IVO, pautada em um modelo consolidado de estudo dos valores culturais, além de sua ampla aceitação e aplicação na literatura de valores organizacionais, o presente trabalho o adotou para a identificação dos valores junto aos órgãos da administração indireta, objeto deste estudo.

\section{CONSTRUÇÃO DA PESQUISA}

A presente investigação pode ser classificada, nos termos propostos por Vergara (2000), como uma pesquisa descritiva, pois objetivou levantar as percepções dos servidores acerca dos valores organizacionais em quatro instituições que representam as diferentes figuras da administração indireta federal, quais sejam: autarquia, fundação pública, empresa pública e sociedade de economia mista. A adoção de abordagem quantitativa nos procedimentos de coleta e análise de dados possibilitou a identificação da hierarquia de valores organizacionais compartilhados, conforme a percepção dos servidores em diferentes posições hierárquicas e tipos de entidade analisadas.

\subsection{POPULAÇÃO E AMOSTRA}

A população do estudo foi constituída por 242 servidores de quatro instituições públicas da administração indireta federal, sediadas na região sul de Minas Gerais, as quais não serão aqui identificadas, dado que a autorização para a coleta de dados foi obtida mediante a condição de que seus nomes não fossem divulgados. A escolha dessas instituições, assim como a delimitação da amostra de 128 servidores envolvidos no estudo, se deu pelo critério de acessibilidade, tratando-se, portanto, de uma amostra acidental (não probabilística), conceitualmente definida como aquela em que o critério de inclusão se dá pela acessibilidade dos sujeitos ou pelo fato de estarem em um determinado lugar, em determinada hora (KISH, I996; SARRIÁ; GUARDIÃ; FREIXA, I999; SCARPARO, 2000).

Os servidores participantes do estudo têm em média 40 anos, sendo $52,4 \%$ mulheres. A maioria dos respondentes é casada $(66,9 \%)$, possui renda familiar de mais de sete salários mínimos $(59 \%)$ e escolaridade de nível superior $(55,6 \%)$. O tempo médio de serviço é de I3,9 anos, entretanto há servidores que contam desde I até 30 anos de trabalho na instituição. Quanto à distribuição dos participantes nas quatro entidades pesquisadas, tem-se que $25 \%$ deles atuam na autarquia, I7,2\% na fundação pública, 36,7\% na empresa pública e 2I,I\% na sociedade de economia mista. 


\subsection{INSTRUMENTOS UTILIZADOS}

Com o objetivo de coletar as informações necessárias ao desenvolvimento do estudo, foi utilizado o IVO, acompanhado de uma ficha sociodemográfica. O IVO contém 36 itens, aos quais os participantes respondem segundo uma escala de sete pontos, variando gradualmente entre $\circ$ (nada importante) e 6 (extremamente importante). Os itens do IVO são distribuídos e agrupados em seis fatores, cujos coeficientes alfa oscilam entre 0,77 e o,87 (TAMAYO; MENDES; PAZ, 2000). Cada um desses fatores corresponde aos diferentes polos axiológicos anteriormente descritos e agrupa diferentes tipos de valores, conforme pode ser visualizado no Quadro I.

\section{QUADRO I}

\section{AGRUPAMENTO DOS VALORES POR POLOS AXIOLÓGICOS}

\begin{tabular}{ll}
\hline POLOS AXIOLÓGICOS & VALORES ORGANIZACIONAIS \\
\hline Autonomia $(\alpha=0,83)$ & $\begin{array}{l}\text { Criatividade, curiosidade, eficiência, eficácia, reconhecimento, } \\
\text { competência, prazer, inovação, realização e liberdade. }\end{array}$ \\
\hline Conservadorismo $(\alpha=0,77)$ & $\begin{array}{l}\text { Disciplina, honestidade, lealdade, limpeza, ordem, polidez, } \\
\text { prestígio, segurança, sensatez e sigilo. }\end{array}$ \\
\hline Hierarquia $(\alpha=0,87)$ & $\begin{array}{l}\text { Fiscalização, hierarquia, obediência, poder, pontualidade, } \\
\text { rigidez, supervisão, tradição e autoridade. }\end{array}$ \\
\hline Igualitarismo $(\alpha=0,85)$ & $\begin{array}{l}\text { Democracia, descentralização, justiça, cogestão, coleguismo, } \\
\text { igualdade, cooperação, comunicação, respeito e equidade. }\end{array}$ \\
\hline Domínio $(\alpha=0,84)$ & $\begin{array}{l}\text { Ambição, audácia, competitividade, domínio, previsibilidade, } \\
\text { produtividade, satisfação dos clientes e sucesso. }\end{array}$ \\
\hline Harmonia $(\alpha=0,85)$ & $\begin{array}{l}\text { Integração, interdependência, ética, tolerância, intercâmbio, } \\
\text { preservação, equilíbrio, respeito à natureza e espontaneidade. }\end{array}$ \\
\hline
\end{tabular}

Fonte: Adaptado de Tamayo (2008).

A ficha sociodemográfica foi estruturada para coletar informações relativas a faixa etária, gênero, estado civil, renda familiar mensal, nível de instrução, tempo de serviço e posição hierárquica na instituição, de modo a permitir a identificação do perfil dos respondentes. 


\subsection{COLETA DE DADOS}

A coleta das informações necessárias à realização do estudo ocorreu em quatro momentos, envolvendo os servidores atuantes em cada uma das instituições participantes do estudo. Todos os participantes da pesquisa receberam um protocolo contendo o IVO e a ficha sociodemográfica. Além disso, o material apresentava informações sobre os objetivos da pesquisa e instruções gerais para o preenchimento dos questionários.

As atividades de coleta se deram por meio de visitas aos locais de trabalho dos servidores, e os procedimentos variaram em função da disponibilidade de tempo dos pesquisados, de forma que, na maioria dos casos, o questionário foi respondido prontamente, mas, em outros, foi marcada uma data para a devolução dele. Durante o processo, foi assegurada a preservação da identidade dos respondentes, que foram requisitados a assinar um Termo de Consentimento Livre e Esclarecido.

\subsection{ANÁLISE DOS DADOS}

As informações obtidas por meio da aplicação dos questionários foram registradas na forma de banco de dados do Statistical Package of Social Sciences (SPSS). Os escores nos fatores do IVO foram estimados pela média dos pontos atribuídos pelos participantes aos itens que compõem cada fator. Os dados foram, então, analisados por meio de procedimentos estatísticos descritivos (média, desvios padrão e frequências) e inferenciais (testes te Anova), de forma a delinear o perfil dos respondentes e identificar a hierarquia de valores organizacionais que orientam a atuação nas instituições envolvidas no estudo.

\section{RESULTAdOS}

Com vistas a identificar a percepção dos respondentes acerca dos valores organizacionais praticados nas instituições públicas estudadas e tecer uma comparação dos resultados obtidos entre os servidores em diferentes posições hierárquicas e em diferentes tipos de entidade da administração indireta, os dados foram analisados em duas fases, que serão apresentadas e discutidas nas seções subsequentes. 


\subsection{VALORES ORGANIZACIONAIS: PERCEPÇÃO DOS SERVIDORES EM DIFERENTES POSIÇÕES HIERÁRQUICAS}

Na primeira fase de análise dos dados, procedeu-se à identificação das prioridades axiológicas, segundo a percepção dos servidores em cargos de gerência e subordinados. Foram, então, computados dois conjuntos de escores nos fatores do IVO e aplicados os testes te Anova para comparar, respectivamente, as médias de cada fator entre os dois grupos de respondentes (gerentes e subordinados) e as médias correspondentes aos seis fatores do IVO para cada um dos grupos.

Os resultados obtidos nessa fase apontaram a existência de diferenças significativas entre as médias dos seis fatores do IVO para os servidores em cargos de gerência $(F=7,83 ; p<0,001)$ e para os servidores subordinados $(F=19,29$;

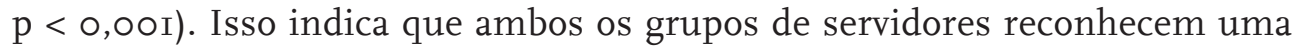
ordem de importância, segundo a qual os valores são hierarquizados nas instituições. Conforme exposto na Tabela I, no caso dos servidores em cargos de gerência, a percepção é de que os valores mais importantes para a organização são, nesta ordem, a autonomia, a hierarquia e o conservadorismo. Os servidores subordinados, por sua vez, percebem outra ordem de prioridades axiológicas, na qual se mostram mais relevantes, primeiramente, os valores de hierarquia e conservadorismo, seguidos pelos de autonomia.

TABELA I

HIERARQUIA DE VALORES ORGANIZACIONAIS CONFORME A PERCEPÇÃO DE SERVIDORES GESTORES E SUBORDINADOS

\begin{tabular}{lccc}
\hline & \multicolumn{3}{c}{ MÉDIA DE PRIORIZAÇÃO DOS VALORES } \\
\cline { 2 - 4 } POLOS AXIOLÓGICOS & $\begin{array}{c}\text { PERCEPÇÃO DE } \\
\text { SERVIDORES GESTORES } \\
\text { MÉDIA (DP) }\end{array}$ & $\begin{array}{c}\text { PERCEPÇÃO DE SERVIDORES } \\
\text { SUBORDINADOS } \\
\text { MÉDIA (DP) }\end{array}$ & TESTES $t$ \\
\hline Autonomia & $4,41(0,84)$ & $3,93(1,01)$ & $\mathrm{t}=1,86 ; \mathrm{p}<0,05$ \\
\hline Conservadorismo & $4,19(0,85)$ & $4,23(0,85)$ & $\mathrm{t}=-0,18 ; \mathrm{p}>0,05$ \\
\hline Hierarquia & $4,35(0,71)$ & $4,29(0,85)$ & $\mathrm{t}=0,27 ; \mathrm{p}>0,05$ \\
\hline Igualitarismo & $3,91(1,10)$ & $3,57(0,97)$ & $\mathrm{t}=1,31 ; \mathrm{p}>0,05$ \\
\hline Domínio & $3,51(1,19)$ & $3,92(1,02)$ & $\mathrm{t}=-1,47 ; \mathrm{p}>0,05$ \\
\hline Harmonia & $3,21(1,32)$ & $3,46(1,36)$ & $\mathrm{t}=-0,72 ; \mathrm{p}>0,05$ \\
\hline
\end{tabular}

$\mathrm{DP}=$ desvio padrão.

Fonte: Elaborada pelos autores. 
Constata-se, portanto, que, embora todos os servidores estejam em concordância sobre o conjunto dos principais valores presentes na instituição, discordam, principalmente, a respeito do grau de importância atribuído aos valores de autonomia. Os gestores tendem a perceber que esses valores são os mais relevantes para a instituição, ao contrário dos demais servidores. Os resultados do teste $t$ contribuem para reafirmar essa distinção, já que as médias do polo autonomia foram as únicas para as quais se identificou diferença estatisticamente significativa entre as percepções de gestores e subordinados $(\mathrm{M}=4,4 \mathrm{I}$ e $\mathrm{M}=3,93$, respectivamente).

Retomando as considerações de Tamayo, Mendes e Paz (2000), a análise da percepção sobre os valores organizacionais praticados fornece indícios sobre a forma como os objetivos gerais da organização são captados por seus membros. Logo, os servidores em cargos de gerência, partindo de sua posição que, por definição, pressupõe maior autonomia do que aquela conferida aos demais servidores, podem estar generalizando a imagem que captam da organização. Há que se considerar também a possibilidade de que os valores de autonomia, sendo relacionados aos princípios de maior agilidade e flexibilidade, enfatizados na reforma gerencial, tenham sido introduzidos nas organizações públicas ao longo dos últimos anos, em um processo de transformação que pode estar favorecendo a convivência de diferentes interpretações acerca das prioridades axiológicas nas instituições estudadas.

Cumpre observar, ainda, que os valores de autonomia e conservadorismo, originalmente polos axiológicos em uma dinâmica de oposição (SCHWARTZ, I999), convivem nas instituições analisadas como valores prioritários. Tal resultado se encontra em consonância com o que foi apontado por Tamayo, Mendes e Paz (2000), no processo de validação do IVO, de que, à exceção dos valores de hierarquia e igualitarismo, aqueles relacionados às demais dimensões tenderiam a não se mostrar conflituosos no ambiente organizacional. Nesse sentido, os achados aqui obtidos corroboram as reflexões tecidas pelos autores do IVO acerca da possibilidade de uma convivência pacífica entre elementos culturais antagônicos nas instituições, tal como tende a ocorrer no contexto cultural mais amplo em que se inserem, ou seja, na cultura brasileira.

Quanto aos polos axiológicos considerados menos relevantes, verifica-se que os servidores em cargos de gerência atribuem que são, nesta ordem, a harmonia e o domínio, ao passo que os demais servidores entendem que são a harmonia e o igualitarismo. Assim, embora haja concordância de que não são relevantes para as instituições analisadas o intercâmbio e a cooperação com outras organizações, além da interação harmoniosa com o meio ambiente, há discordância quanto ao peso dado aos valores de domínio e igualitarismo. Entretanto, por se tratar de 
valores que não são prioritários, as diferenças de percepção tendem a provocar menores impactos no relacionamento entre gerência e demais servidores.

O mesmo não se pode afirmar sobre as diferenças de percepção acerca dos valores considerados prioritários nas instituições analisadas, pois trazem implicações que não podem ser negligenciadas. Uma delas se assenta nas dificuldades que tais diferenças podem provocar nos processos de comunicação organizacional, ocasionando distorções na forma como atitudes e mensagens são emitidas, recebidas e decodificadas por parte de gestores e subordinados. A outra se refere a um aspecto a ser problematizado, o qual se refere à condução de pesquisas que tomam unicamente a perspectiva dos gestores na identificação dos valores organizacionais e desconsideram que essa visão pode não traduzir integralmente a realidade da organização.

O estudo de Macêdo et al. (2005), por exemplo, generaliza os resultados obtidos a partir das percepções de dirigentes, assumindo que estas traduzem os valores organizacionais praticados nas entidades pesquisadas, o que reflete uma concepção existente em estudos de cultura organizacional, segundo a qual seriam os gestores os elementos-chave na investigação da cultura (SCHEIN, I986). Tal concepção se encontra presente nas pesquisas desenvolvidas sob a denominada perspectiva da integração, que supõe a existência de consenso, especialmente, em torno de um conjunto de valores compartilhados na organização, defendendo a noção de que os líderes podem articular seus próprios valores e promover um comprometimento em torno destes (MARTIN; FROST, 200I).

Entretanto, assim como no presente estudo, Freire (2009) também já havia observado divergências na percepção de valores organizacionais entre trabalhadores e alta administração, em uma empresa do setor de terceirizáveis, o que reforça a importância de se atentar para as possíveis limitações envolvidas nas abordagens que tomam apenas a posição dos gestores. Tal estratégia de considerar as diferenças de percepção e opinião associadas a posições, tarefas e cargos, por exemplo, já vinha sendo adotada nos estudos desenvolvidos sob a perspectiva da diferenciação, para a qual a cultura não é unitária, mas composta por um conjunto de subculturas sobrepostas e abrigadas nas fronteiras da organização (MARTIN; FROST, 200I).

Entende-se, todavia, e em conformidade com as reflexões de Martin e Frost (200I), que não se pode ignorar a existência de consenso em torno de certos valores, como aqui se verificou nos resultados obtidos em relação àqueles de hierarquia e conservadorismo, tampouco desconsiderar que existem outros que geram conflitos e discordâncias, conforme se observou no caso dos valores de autonomia. Por essa razão, embora a percepção dos gestores possa contribuir para compreender os valores praticados em uma organização, ela não possibili- 
tará captar as inconsistências existentes. Nessa vertente, os achados aqui obtidos se mostram coerentes com a noção de que a cultura e, por consequência, os valores são construídos socialmente (BERGER; LUCKMANN, I985), e, portanto, a busca de sua compreensão deveria envolver representativamente a totalidade do tecido social analisado.

\subsection{VALORES ORGANIZACIONAIS: PERCEPÇÃO DOS SERVIDORES EM DIFERENTES TIPOS DE ENTIDADE DA ADMINISTRAÇÃO INDIRETA}

Na segunda fase de análise dos dados, procedeu-se à identificação das prioridades axiológicas segundo a percepção dos servidores em cada uma das entidades envolvidas no estudo. Dessa forma, foram obtidos quatro conjuntos de escores nos fatores do IVO. Os testes Anova foram, então, aplicados para comparar as médias correspondentes aos seis fatores do IVO em cada instituição e para comparar as médias de cada fator entre as quatro instituições analisadas (autarquia, fundação pública, empresa pública e sociedade de economia mista).

Tomando-se os resultados da comparação entre as médias dos seis fatores do IVO em cada instituição, constatou-se diferença estatisticamente significativa, sendo possível afirmar que os servidores percebem a existência de uma hierarquia de importância atribuída aos diferentes valores organizacionais tanto na autarquia ( $\mathrm{F}=8,07$; $\mathrm{p}<$ 0,००I) quanto na fundação pública $(\mathrm{F}=6, \mathrm{OI} ; \mathrm{p}<\mathrm{0,00I})$, na empresa pública $(\mathrm{F}=\mathrm{I5}, 68 ; \mathrm{p}<0,00 \mathrm{I})$ e na sociedade de economia mista $(\mathrm{F}=4,52 ; \mathrm{p}<0, \mathrm{OI})$.

Como é possível visualizar na Tabela 2, os servidores da autarquia percebem que é dada maior importância, nesta ordem, aos valores de hierarquia, conservadorismo e autonomia. Esse mesmo conjunto de valores é enfatizado na fundação pública, havendo pequena inversão na ordem de prioridades, de forma que se percebe que o conservadorismo é mais valorizado do que a hierarquia. Atentando para os casos da empresa pública e da sociedade de economia mista, observa-se que o domínio passa a integrar o grupo de valores considerados mais relevantes, juntamente com a hierarquia e o conservadorismo. A diferença entre ambas se situa no fato de que, na empresa pública, são apontados como prioritários, nesta ordem, os valores de hierarquia, domínio e conservadorismo, ao passo que, na sociedade de economia mista, embora os valores de hierarquia também sejam vistos como os mais relevantes, aqueles de conservadorismo têm primazia perante os de domínio. 
TABELA 2

HIERARQUIA DE VALORES ORGANIZACIONAIS CONFORME A PERCEPÇÃO DE SERVIDORES EM DIFERENTES TIPOS DE ENTIDADE DA ADMINISTRAÇÃO INDIRETA

\begin{tabular}{|c|c|c|c|c|c|}
\hline \multirow[b]{2}{*}{$\begin{array}{l}\text { POLOS } \\
\text { AXIOLÓGICOS }\end{array}$} & \multicolumn{5}{|c|}{ MÉDIA DE PRIORIZAÇÃO DOS VALORES } \\
\hline & $\begin{array}{l}\text { AUTARQUIA } \\
\text { MÉDIA (DP) }\end{array}$ & $\begin{array}{l}\text { FUNDAÇÃO } \\
\text { PÚBLICA } \\
\text { MÉDIA (DP) }\end{array}$ & $\begin{array}{c}\text { EMPRESA } \\
\text { PÚBLICA } \\
\text { MÉDIA (DP) }\end{array}$ & $\begin{array}{c}\text { SOCIEDADE DE } \\
\text { ECON. MISTA } \\
\text { MÉDIA (DP) }\end{array}$ & TESTES ANOVA \\
\hline Autonomia & $4,22(1,10)$ & $3,61(1,12)$ & $3,85(0,86)$ & $4,31(0,93)$ & $F=2,54 ; p>0,05$ \\
\hline Conservadorismo & $4,32(1,14)$ & $4,23(1,03)$ & $3,98(0,61)$ & $4,57(0,87)$ & $F=2,76 ; p<0,05$ \\
\hline Hierarquia & $4,39(0,90)$ & $4,14(0,93)$ & $4,15(0,77)$ & $4,66(0,74)$ & $F=2,23 ; p>0,05$ \\
\hline Igualitarismo & $3,79(1,14)$ & $3,33(1,04)$ & $3,45(0,86)$ & $3,95(1,00)$ & $F=2,11 ; p>0,05$ \\
\hline Domínio & $3,57(1,33)$ & $2,85(1,16)$ & $4,05(0,68)$ & $4,50(0,71)$ & $F=10,79 ; p<0,01$ \\
\hline Harmonia & $3,23(1,35)$ & $2,87(1,36)$ & $3,37(1,10)$ & $3,92(1,36)$ & $F=1,82 ; p>0,05$ \\
\hline
\end{tabular}

$\mathrm{DP}=$ desvio padrão.

Fonte: Elaborada pelos autores.

Com base na observação dos resultados, cumpre destacar dois aspectos. O primeiro diz respeito ao fato de que os valores de hierarquia e conservadorismo são enfatizados pelos servidores nas quatro instituições analisadas. O segundo concerne à existência de um elemento de diferenciação que divide as organizações estudadas em dois grupos: I. autarquia e fundação pública, pela relevância atribuída aos valores de autonomia; e 2. empresa pública e sociedade de economia mista, pela importância conferida aos valores de domínio.

Os resultados do teste Anova, para a comparação das médias de cada fator do IVO entre as instituições analisadas, contribuem para reforçar tal diferenciação na estrutura de valores entre os dois grupos de instituições apontados, ao mostrarem que os polos de domínio e conservadorismo são os únicos cujas médias apresentam diferenças estatisticamente significativas entre as instituições. Logo, tem-se que o grau em que os valores de domínio são reforçados oscila entre as instituições, sendo nitidamente percebidos como mais relevantes para a sociedade de economia mista $(M=4,50)$ e a empresa pública $(M=4,05)$ do que para a autarquia $(\mathrm{M}=3,57)$ e a fundação pública $(\mathrm{M}=2,87)$. 
Os dois aspectos destacados ensejam algumas reflexões. No que tange à importância conferida aos valores de hierarquia e conservadorismo pelas entidades analisadas, cumpre observar que confirmam uma tendência, apontada por Schwartz (I999), de compatibilidade entre essas duas dimensões, dado que a legitimidade da alocação hierárquica fixa de papéis e recursos guarda estreita relação com a manutenção do status quo. Observa-se, ainda, por meio de um breve levantamento de resultados de pesquisas anteriores desenvolvidas no Brasil, utilizando-se o IVO (MENDES; TAMAYO, 200I; BORGES et al., 2002; BORGES; ARGOLO; BAKER, 2006; MACÊDO et al., 2005; PORTO; TAMAYO, 2005; FERNANDES; FERREIRA, 2009; FREIRE, 2009), que os polos hierarquia e conservadorismo estiveram sempre entre os que receberam as avaliações médias mais elevadas, independentemente da esfera de atuação da organização estudada, variando apenas o grau de prioridade a eles atribuído, ainda que, na maioria das vezes, estivessem na primeira ou segunda posição em termos de importância para a organização.

Considera-se, assim, que a ênfase nos valores de hierarquia e conservadorismo pode estar, em parte, relacionada a alguns aspectos culturais nacionais que se destacam em meio à pluralidade e heterogeneidade da cultura brasileira e, em parte, às especificidades das organizações aqui abordadas, as quais se caracterizam por atuarem de forma descentralizada na esfera pública, como órgãos da administração indireta federal.

Focalizando-se a dimensão hierarquia versus igualitarismo, esta diz respeito às orientações que definem a estrutura das organizações, seu sistema social, em termos de distribuição de funções e das relações entre suas diferentes unidades e membros. Assim, quanto mais importância for dada aos valores de hierarquia, mais a organização tenderá a prezar a autoridade, o poder social, a influência, a fiscalização, a obediência, a pontualidade, a rigidez e a supervisão (TAMAYO; MENDES; PAZ, 2000; TAMAYO, 2008). A dimensão autonomia versus conservadorismo se refere à relação entre o indivíduo e o grupo, de forma que, quando a ênfase está mais voltada aos interesses do grupo, a organização tenderá a valorizar a conservação de usos, costumes e estruturas de poder, caracterizando uma orientação para o conservadorismo. Assim, será incentivada a manutenção do status quo e a interdição de comportamentos que possam perturbar as normas e tradições da empresa (TAMAYO; MENDES; PAZ, 2000).

Quando se analisa a relação desses elementos com alguns aspectos da cultura brasileira, observa-se que os traços de hierarquia e personalismo, apontados por Freitas (1997) dentre aqueles mais influentes no âmbito das organizações, se mostram relacionados às dimensões de valores organizacionais anteriormente descritas. Segundo o autor, as características-chave dos traços brasileiros de 
hierarquia e personalismo são, respectivamente, a tendência à centralização do poder e o distanciamento no interior dos grupos, nos quais ocorre a obediência e a aceitação da condição de subordinação; e a primazia do grupo sobre o indivíduo, caracterizando uma sociedade baseada em relações pessoais, na qual são valorizadas a polidez e a cordialidade no trato com as pessoas. Tamayo (I999) também observou a existência de familiaridade entre os empregados de organizações brasileiras com modelos hierárquicos, os quais, por definirem de forma clara os papéis e formalidades do relacionamento, proporcionam segurança aos indivíduos ao explicitarem quais são os comportamentos sociais e organizacionais esperados. Portanto, deve-se considerar a possibilidade de que esses traços comuns aos brasileiros contribuam para explicar a prioridade conferida aos valores de hierarquia e conservadorismo nas instituições públicas aqui analisadas.

Nestas, os valores organizacionais de hierarquia se expressaram principalmente em termos de preocupação com o cumprimento de horários e compromissos, respeito às pessoas em cargos de chefia, às regras e normas estabelecidas pela organização e aos níveis de autoridade, além da tradição de respeito às ordens, os quais descrevem os itens do IVO agrupados no fator hierarquia que receberam as maiores médias. Denotam, assim, que nessas instituições a ênfase é colocada principalmente nos aspectos da hierarquia que dizem respeito à valorização da autoridade, do poder social, da obediência e da pontualidade. Quanto aos valores de conservadorismo, destacaram-se a fidelidade à organização, a segurança de pessoas e bens e o clima de relacionamento amistoso e de ajuda mútua entre os empregados, sinalizando uma ênfase na lealdade, segurança e polidez nas relações organizacionais.

Tais resultados ilustram algumas especificidades relacionadas à forma de expressão dos valores de hierarquia e conservadorismo no âmbito das instituições públicas da administração indireta federal. Por exercerem funções descentralizadas, porém vinculadas a um órgão da administração central, tais instituições são controladas pelo Estado e submetidas às normas de ordem pública. Por meio dessas características, é possível compreender os elementos da hierarquia manifestos como valorização da autoridade e da pontualidade e os do conservadorismo expressos na valorização da lealdade e segurança. Nota-se, ainda, que são relacionados a alguns aspectos centrais do modelo burocrático de administração pública, que se caracteriza por um tipo de cultura organizacional hierarquizada, marcada por referenciais de responsabilidade e autoridade, orientada por regras formais que visam à padronização nas atividades a serem executadas e ao controle de procedimentos (MATIAS-PEREIRA, 2009), elementos concernentes aos itens do IVO mencionados entre aqueles com maior pontuação.

A presença desses valores no contexto de instituições públicas quase 20 anos depois da reforma gerencial é parte de uma realidade que vem sendo discutida 
por outros autores. Motta (2013), por exemplo, comenta que, a despeito das tentativas de descentralização e flexibilização, a Nova Administração Pública não extinguiu os controles tradicionais, criando, em muitos casos, novas centralizações, regras e níveis hierárquicos, a ponto de ocasionar um aumento do peso burocrático. Secchi (2009) também já havia apontado que, embora as reformas administrativas preguem a substituição progressiva do modelo burocrático, suas características essenciais são compartilhadas entre os novos modelos de gestão, os quais continuam enfatizando o controle, de modo que não se configuram como modelos de ruptura.

Outra questão discutida diz respeito ao fato de que a Nova Administração Pública carrega os valores culturais dos países em que foi criada, razão pela qual se mostrou mais bem-sucedida em nações dominadas por pragmatismo gerencial, baixa imposição de normas burocráticas e maior democracia na gestão (CHRISTENSEN; LAEGREID, 2007 apud MOTTA, 20I3) do que naquelas caracterizadas por extensa burocracia, acentuado formalismo e forte autoridade hierárquica (MOTTA, 20I3), reconhecidos como traços típicos da cultura brasileira.

Tomando, por sua vez, as distinções nas orientações valorativas das organizações estudadas, que se manifestaram, principalmente, em termos de maior prioridade aos valores de autonomia na autarquia e na fundação pública e aos de domínio na empresa pública e na sociedade de economia mista, cumpre também tecer algumas reflexões. Primeiramente, tal resultado demonstra relação com o tipo de atividade desenvolvida que, na empresa pública e na sociedade de economia mista, é de caráter econômico. Isso torna explicável o fato de que os valores de domínio tenham sido percebidos entre os prioritários apenas nessas duas instituições, uma vez que se referem à importância dada ao sucesso organizacional e à satisfação dos clientes (TAMAYO; MENDES; PAZ, 2000), expressando características de organizações que enfatizam a preponderância sobre os concorrentes e sobre o meio ambiente (PORTO; TAMAYO, 2005).

Dentre os itens do IVO que compõem os valores agrupados no polo domínio, observou-se que, tanto na empresa pública como na sociedade de economia mista, as maiores médias foram atribuídas àqueles que descrevem a busca de melhor posição e manutenção de superioridade em relação ao mercado, preocupação com o aumento da produção e prestação dos serviços, êxito nos empreendimentos e conquista de clientes em relação à concorrência. Destacaram-se, portanto, os aspectos de competitividade, produtividade, satisfação dos clientes e sucesso.

No que tange aos valores de autonomia, percebidos entre os mais relevantes apenas na autarquia e na fundação pública, entende-se que tal resultado pode ser um reflexo das orientações decorrentes da reforma que buscou implantar 
o modelo gerencial na administração pública brasileira. Sendo as autarquias e fundações públicas instituições que se caracterizam, respectivamente, por desempenhar funções próprias e típicas do Estado e atividades do Estado na ordem social, tornam-se objetos mais prováveis de intervenção para a melhoria do desempenho do serviço público, em termos de maior agilidade, eficiência e flexibilidade, do que as empresas públicas e as sociedades de economia mista. A percepção dos gestores de que os valores de autonomia constituem a principal prioridade nas instituições analisadas reforça essa explicação, uma vez que se trata dos servidores mais diretamente alcançados pelas orientações e diretrizes da administração central.

Uma observação dos resultados do estudo de Borges, Argolo e Baker (2006) propicia a identificação de elementos que favorecem essa interpretação, à medida que descrevem mudanças de valores em uma autarquia, por meio de avaliações realizadas nos anos de 2000 e de 2003 , em que se observa, dentre outros aspectos, que os valores de autonomia estiveram entre os que mais cresceram em importância para a instituição no período. O levantamento dos itens do IVO agrupados no polo autonomia, aos quais, no presente estudo, foram atribuídas as maiores médias, também contribui para esse entendimento, pois se referem à competência, eficiência, criatividade e inovação, expressas na busca constante de informações e novidades, na capacidade de inovar na organização e de introduzir novidades no trabalho, os quais se constituem como valores centrais para a Nova Administração Pública, orientada ao cliente-cidadão, com foco em resultados e na busca pela flexibilização administrativa (MATIAS-PEREIRA, 2009).

Conforme salientam Tamayo, Mendes e Paz (2000), nas organizações em que predominam os valores de autonomia, tende-se a enfatizar a inovação, o teste de novas soluções, de novas formas de pensar, agir e executar o trabalho. No caso aqui analisado, entretanto, em que os valores de conservadorismo são prioritários perante os de autonomia, pode-se dizer que essas instituições prezam pela competência, criatividade e inovação, desde que não ameacem as relações pessoais instituídas, a lealdade e a segurança nas ações organizacionais. Como lembra Motta (2008), a eficiência e a flexibilidade administrativas não se constroem meramente pela introdução de instrumentos modernos de gestão, mas, sobretudo, pela ruptura das características sociopolíticas existentes na gestão pública, pois, em um contexto em que as ações gerenciais visam mais ao domínio dos recursos de poder, as inovações significativas só poderão ser introduzidas por meio de conquistas graduais, em que se promova a transferência do poder, da responsabilidade e dos recursos, permitindo um maior número de decisões próximas ao local da ação. 


\section{CONSIDERAÇÕES FINAIS}

O presente estudo teve como objetivo central identificar a percepção dos servidores acerca dos valores organizacionais que orientam a gestão nas instituições públicas da administração indireta, visando observar a ocorrência de variações nessa percepção de acordo com a posição hierárquica e o tipo de entidade a que pertencem. Com esse propósito, focalizou o caso de quatro instituições, que correspondem às diferentes figuras da administração indireta federal, as quais exercem atividades na região sul de Minas Gerais.

Com base na comparação das percepções de valores por parte de servidores em cargos de gerência e subordinados, foi possível verificar que, embora estejam em concordância sobre o conjunto dos valores que constituem as prioridades axiológicas das instituições analisadas, discordam a respeito de sua organização numa hierarquia de importância. Assim, ao passo que os gestores perceberam como mais importantes para a organização os valores de autonomia, hierarquia e conservadorismo, os subordinados identificaram outra ordem de prioridades, segundo a qual os valores de hierarquia e conservadorismo se mostraram mais relevantes do que os de autonomia. São discutidas as implicações desses achados para o relacionamento entre gerência e subordinados, para os processos de comunicação organizacional nas instituições estudadas e para a adoção de desenhos de pesquisa cuja avaliação dos valores organizacionais é realizada unicamente sob a perspectiva dos gestores. Salienta-se que, sendo a cultura e, por consequência, os valores construídos socialmente (BERGER; LUCKMANN, I985), a busca de sua compreensão deveria envolver representativamente a totalidade do tecido social analisado.

A comparação das prioridades axiológicas entre as diferentes entidades da administração indireta abordadas possibilitou também tecer algumas considerações acerca da relação entre a natureza das atividades desempenhadas e os valores organizacionais adotados. Observou-se que os valores de hierarquia e conservadorismo foram percebidos como prioritários nas quatro instituições analisadas, ao passo que aqueles de autonomia foram enfatizados apenas na autarquia e na fundação pública, e os de domínio apenas na empresa pública e na sociedade de economia mista. Assim, ainda que alguns elementos de diferenciação tenham sido identificados, as percepções dos servidores nas diferentes instituições apontam para uma predominante similaridade na hierarquia de valores entre as mesmas. Considerando que, mesmo nas instituições em que os valores de autonomia estiveram entre os prioritários, maior relevância foi atribuída aos valores de conservadorismo, concluiu-se que nestas a competência, a criatividade e a inovação são encorajadas desde que não constituam uma ameaça às relações pessoais instituídas, à lealdade e à segurança nas ações organizacionais. 
Dessa forma, entende-se que os achados do presente estudo contribuem para desafiar a noção defendida por autores como Oliveira, Ferreira e Lima (2010, p. I) de que a gestão pública contemporânea "distancia-se cada vez mais de práticas baseadas na centralização das decisões, hierarquia traduzida no princípio de unidade de comando, estrutura piramidal de poder, rotinas rígidas, controle dos processos administrativos e alta profissionalização" e se espelha na gestão das empresas privadas, enfatizando a flexibilidade, a qualidade, a competência, a inovação e a mudança. O que se observou neste estudo foi uma tímida manifestação no sentido de valorização da dimensão autonomia, a qual, entretanto, não constituiu a principal prioridade das instituições em que foi identificada. Segundo a percepção dos servidores subordinados, estas continuam marcadas primordialmente por valores relacionados à conservação de sua estrutura atual, seus costumes, suas normas e tradições, além de expressarem foco na autoridade, na obediência e no poder social.

Por fim, é importante atentar para as limitações da pesquisa, uma vez que, tendo sido desenvolvida junto a quatro instituições da administração indireta federal, não se pode pretender a generalização dos resultados obtidos à totalidade das entidades públicas. Além disso, o levantamento de dados restringiu-se à aplicação de questionário estruturado, o que não permitiu captar e discutir com maior profundidade as peculiaridades das percepções de gerentes e subordinados e de cada tipo de instituição analisada. Identifica-se, portanto, uma oportunidade para novas pesquisas no campo, que permitam verificar a replicação desses achados em diferentes órgãos da administração indireta, sediados em outras regiões do país, bem como sua aplicação junto à administração direta, possibilitando ampliar o quadro de comparações e identificar tendências. São também necessárias pesquisas que adotem uma combinação de diferentes técnicas de coleta de dados, numa triangulação metodológica, que proporcione diferentes ângulos para uma observação mais acurada do fenômeno.

A despeito das limitações apontadas, entende-se que o presente estudo apresentou algumas contribuições. O enfoque em quatro instituições públicas da administração indireta federal, as quais fazem parte de um conjunto de órgãos responsáveis por parcela significativa da prestação de serviços públicos no Brasil, permitiu vislumbrar em que medida os valores cultivados no âmbito delas se encontram alinhados às propostas e inovações na gestão pública, difundidas a partir da reforma dos anos I990. Além disso, a comparação entre servidores em cargos de gerência e subordinados possibilitou observar o quadro sob diferentes perspectivas, contribuindo para discutir as implicações da posição hierárquica na percepção dos valores organizacionais. 


\section{ORGANIZATIONAL VALUES IN BRAZILIAN PUBLIC INSTITUTIONS: PERCEPTIONS OF CIVIL SERVANTS IN DIFFERENT HIERARCHICAL POSITIONS AND TYPES OF INDIRECT ADMINISTRATION ENTITY}

\section{ABSTRACT}

The aim of the study was to identify the civil servants' perceptions about organizational values in public institutions of indirect federal administration and to observe variations in conformity to hierarchical position and type of entity. Four institutions were focused, using a sample of 128 civil servants, to whom the Organizational Values Inventory (TAMAYO; MENDES; PAZ, 2000) and a socio-demographic form were applied. The results showed that there is agreement between managers and subordinates about the set values that constitute the priorities of the institutions analyzed, but the managers consider more relevant the values of autonomy and the subordinates the values of hierarchy. Regarding the value priorities in each entity, the civil servants' perceptions indicated some elements of differentiation, so that the autarchy and the public foundation emphasized the values of autonomy and the public company and the mixed capital company emphasized the values of mastery. The similarity in values structures, however, prevailed among the institutions, since they attributed greater relevance to the values of hierarchy and conservatism. It shows that these institutions, despite the efforts implemented since the reform in the I990s, are still characterized by values related to conservation of its structure, customs, norms and traditions. Furthermore, they focus on the authority, obedience and social power. The implications, limitations and contributions of the study are discussed, with suggestions for future research.

\section{KEYWORDS}

Organizational values; Perception of values; Public management; Public institutions; Indirect administration. 


\section{RESUMEN}

El objetivo del estudio fue identificar la percepción de los valores de la organización en las instituciones públicas de la administración federal indirecta, con el fin de observar la ocurrencia de variaciones en función de la posición jerárquica de los servidores y de los tipos de entidades de la administración indirecta analizados. Para este propósito, centrado en el caso de cuatro instituciones, utilizando una muestra de i28 servidores, a los que se aplicó el Inventario de Valores Organizacionales (TAMAYO; MENDES; PAZ, 2000). Los resultados mostraron que a pesar de que existe un acuerdo entre directivos y subordinados en el conjunto de valores que constituyen las prioridades de las instituciones analizadas, directivos creen que son más relevantes los valores de autonomía y subordinados, los valores de jerarquía. En cuanto a las prioridades de valores en las diferentes entidades, las percepciones señalar algunos elementos de diferenciación representados por la importancia de la autonomía para la autarquía y para la fundación pública y el dominio para la empresa pública y la sociedad de economía mixta. Prevalece, sin embargo, la similitud en la jerarquización de valores, con mayor énfasis en la jerarquía y el conservadurismo, que muestran que estas instituciones, a pesar de las iniciativas puestas en marcha a partir de la reforma de la gestión pública en la década de I990, permanecen caracterizadas principalmente por los valores relacionados con la conservación de su estructura, costumbres, normas y tradiciones, además de un enfoque en la expresa autoridad, la obediencia y el poder social. Las implicaciones, limitaciones y aportaciones del estudio se discuten, con sugerencias para investigaciones futuras.

\section{PALABRAS CLAVE}

Valores de la organización; Percepción de los valores; Servidores públicos; Instituciones públicas; Administración indirecta. 


\section{REFERÊNCIAS}

ABRÚCIO, F. L. Trajetória recente da gestão pública brasileira: balanço crítico e renovação da agenda de reformas. Revista de Administração Pública, v. 4I, n. esp., p. 67-86, 2007.

ANDION, C. Por uma nova interpretação das mudanças de paradigma na administração pública. Cadernos Ebape.BR, v. IO, n. I, p. I-I9, 2012.

ANDRADE, T.; ESTIVALETE, V. F. B. Valores organizacionais e suporte social no trabalho: a percepção dos colaboradores no setor bancário público e privado. In: ENCONTRO DA ASSOCIAÇÃO NACIONAL DOS PROGRAMAS DE PÓS-GRADUAÇÃO EM ADMINISTRAÇÃO, 34., 20IO, Rio de Janeiro. Anais... Rio de Janeiro: Anpad, 2010.

AZEVEDO, C. B.; LOUREIRO, M. R. Carreiras públicas em uma ordem democrática: entre os modelos burocrático e gerencial. Revista do Serviço Público, ano 54, n. I, p. 45-60, 2003.

BANDEIRA DE MELLO, C. A. Curso de direito administrativo. 26. ed. São Paulo: Malheiros, 2008. BERGER, P.; LUCKMANN, T. A construção social da realidade. Petrópolis: Vozes, I985.

BORGES, L. O.; ARGOLO, J. C. T.; BAKER, M. C. S. Os valores organizacionais e a síndrome de burnout: dois momentos em uma maternidade pública. Psicologia: Reflexão e Crítica, v. I9, n. I, p. $34-43,2006$.

BORGES, L. O. et al. Síndrome de burnout e valores organizacionais: um estudo comparativo em hospitais universitários. Psicologia: Reflexão e Crítica, v. I5, n. I, p. I89-200, 2002.

BRASIL. Decreto-Lei $n^{\circ}$ 200, de 25 de fevereiro de 1967 . Dispõe sobre a organização da Administração Federal, estabelece diretrizes para a Reforma Administrativa e dá outras providências. Diário Oficial [da] Republica Federativa do Brasil, Poder Executivo, Brasília, DF, 27 fev. I967. Seção I, Suplemento, p. 4.

BRESSER PEREIRA, L. C. Uma reforma gerencial da administração pública no Brasil. Revista do Serviço Público, ano 49, n. I, p. 5-42, I998.

CARVALHO FILHO, J. S. Manual de direito administrativo. 2I. ed. Rio de Janeiro: Lumen Júris, 2009. FERNANDES, H. A.; FERREIRA, M. C. O impacto dos valores pessoais e organizacionais no comprometimento com a organização. Psico-USF, v. I4, n. 3, p. 34I-354, 2009.

FERNANDES, K. R.; ZANELLI, J. C. O processo de construção e reconstrução das identidades dos indivíduos nas organizações. Revista de Administração Contemporânea, v. Io, n. I, p. 55-72, 2006.

FREIRE, D. A. L. Valores organizacionais: um estudo de caso no setor de serviços terceirizáveis. In: ENCONTRO DA ASSOCIAÇÃO NACIONAL DOS PROGRAMAS DE PÓS-GRADUAÇÃO EM ADMINISTRAÇÃO, 33., 2009, São Paulo. Anais... São Paulo: Anpad, 2009.

FREITAS, A. B. Traços brasileiros para uma análise organizacional. In: MOTTA, F. C. P.; CALDAS, M. P. (Orgs.). Cultura organizacional e cultura brasileira. São Paulo: Atlas, I997.

HASSAN, A. Human resource development and organizational values. Journal of European Industrial Training, v. 3I, n. 6, p. 435-448, 2007.

KISH, L. Diseño estadístico para la investigación. Madrid: Siglo Veintiuno de España, I996.

KNAFO, A.; ROCCAS, S.; SAGIV, L. The value of values in cross-cultural research. Journal of CrossCultural Psychology, v. 42, n. 2, p. I78-185, 20II.

MACÊDO, K. B. et al. Valores individuais e organizacionais: estudo com dirigentes de organizações pública, privada e cooperativa em Goiás. Cadernos de Psicologia Social do Trabalho, v. 8, p. 29-42, 2005 . 
MARTIN, J.; FROST, P. Jogos de guerra da cultura organizacional: a luta pelo domínio intelectual. In: CLEGG, S. R.; HARDY, C.; NORD, W. R. (Orgs.). Handbook de estudos organizacionais: reflexões e novas direções. São Paulo: Atlas, 200I. v. 2.

MARTINS, H. F. Burocracia e a revolução gerencial - a persistência da dicotomia entre política e administração. Revista do Serviço Público, ano 48, n. I, p. 42-78, I997.

MATIAS-PEREIRA, J. Administração pública comparada: uma avaliação das reformas administrativas do Brasil, EUA e União Européia. Revista de Administração Pública, v. 42, n. I, p. 6I-82, 2008. MATIAS-PEREIRA, J. Manual de gestão pública contemporânea. 2. ed. São Paulo: Atlas, 2009.

MENDES, A. M.; TAMAYO, A. Valores organizacionais e prazer-sofrimento no trabalho. Psico-USF, v. 6, n. I, p. 39-46, 200I.

MINISTÉRIO DO ORÇAMENTO, PLANEJAMENTO E GESTÃO. Boletim estatístico de pessoal. Secretaria de Gestão Pública, v. I7, n. I94, 2012.

MOTTA, P. R. A modernização da administração pública brasileira nos últimos 40 anos. Revista de Administração Pública, v. 4I, n. esp., p. 87-96, 2007.

MOTTA, P. R. Organizações e mudança no setor público: restrições e possibilidades. Cadernos FGV Projetos, ano 2, n. 6, p. 39-44, 2008.

MOTTA, P. R. O estado da arte da gestão pública. Revista de Administração de Empresas, v. 53, n. I, p. 82-90, 20I3.

MOTTA, F. C. P.; VASCONCELOS, I. F. G. Teoria geral da administração. 3. ed. São Paulo: Thomson Learning, 2006.

NEIVA, E. R.; PAZ, M. G. T. Percepção de mudança organizacional: um estudo em uma organização pública. Revista de Administração Contemporânea, v. II, n. I, p. 3I-52, 2007.

OLIVEIRA, O. B.; FERREIRA, M.; LIMA, S. M. P. Estratégias de flexibilização na gestão de recursos humanos: uma análise a partir das reformas administrativas. In: ENCONTRO DA ASSOCIAÇÃO NACIONAL DOS PROGRAMAS DE PÓS-GRADUAÇÃO EM ADMINISTRAÇÃO, 34., 20IO, Rio de Janeiro. Anais... Rio de Janeiro: ANPAD, 2010.

PAULA, A. P. P. Administração pública brasileira: entre o gerencialismo e a gestão social. Revista de Administração de Empresas, v. 45, n. I, p. 36-49, 2005.

PORTO, J. B.; TAMAYO, A. Escala de valores relativos ao trabalho - EVT. Psicologia: Teoria e Pesquisa, v. I9, n. 2, p. 145-152, 2003.

PORTO, J. B.; TAMAYO, A. Valores organizacionais e civismo nas organizações. Revista de Administração Contemporânea, v. 9, n. I, p. 35-52, 2005.

ROS, M. Psicologia social dos valores: uma perspectiva histórica. In: ROS, M.; GOUVEIA, V. V. (Orgs.). Psicologia social dos valores humanos. São Paulo: Senac, 2006.

SARRIÁ, A.; GUARDIÃ, J.; FREIXA, M. Introducción a la estadística em psicologia. Barcelona: Ediciones de la Universitat de Barcelona, I999.

SCARPARO, H. Psicologia e pesquisa. Porto Alegre: Sulina, 2000.

SCHEIN, E. Organizational culture and leadership. San Francisco: Jossey-Bass, I986.

SCHWARTZ, S. H. Are there universal aspects in the structure and contents of human values? Journal of Social Issues, v. 50, p. I9-45, I994a.

SCHWARTZ, S. H. Beyond individualism/collectivism: new cultural dimensions of values. In: KIM, U.; TRIANDIS, H. C.; KÂĞITÇIBAŞI, C.; CHOI, S. C.; YOON, G. (Orgs.). Individualism and collectivism: theory, method and applications. Thousand Oaks: Sage publications, I994b. p. 85-II9. 
SCHWARTZ, S. H. A theory of cultural values and some implications for work. Applied Psychology: An International Review, v. 48, n. I, p. 23-47, I999.

SCHWARTZ, S. H.; BILSKY, W. Toward a universal psychological structure of human values. Journal of Personality and Social Psychology, v. 53, n. 3, p. 550-562, I987.

SCHWARTZ, S. H.; ROS, M. Values in the West: a theoretical and empirical challenge to the individualism-collectivism cultural dimension. World Psychology, v. I, p. 9I-I22, I995.

SECCHI, L. Modelos organizacionais e reformas da administração pública. Revista de Administração Pública, v. 43, n. 2, p. 347-369, 2009.

SILVA, L. P.; FADUL, E. A produção científica sobre cultura organizacional em organizações públicas no período de I997 a 2007: um convite à reflexão. Revista de Administração Contemporânea, v. I4, n. 4, p. 65I-669, 2010.

TAMAYO, A. Valores e clima organizacional. In: PAZ, M. G. T.; TAMAYO, A. (Orgs.). Escola, saúde e trabalho: estudos psicológicos. Brasília: Universidade de Brasília, I999.

TAMAYO, A. Valores organizacionais e comprometimento afetivo. Revista de Administração Mackenzie, v. 6, n. 3, p. 192-213, 2005.

TAMAYO, A. Contribuições ao estudo dos valores pessoais, laborais e organizacionais. Psicologia: Teoria e Pesquisa, v. 23, n. esp., p. I7-24, 2007 a.

TAMAYO, A. Hierarquia de valores transculturais e brasileiros. Psicologia: Teoria e Pesquisa, v. 23, p. 7-I5, $2007 \mathrm{~b}$.

TAMAYO, A. Valores organizacionais. In: SIQUEIRA, M. M. M. (Org.). Medidas do comportamento organizacional. Porto Alegre: Artmed, 2008.

TAMAYO, A.; BORGES, L. O. Valores do trabalho e das organizações. In: ROS, M.; GOUVEIA, V. V. (Orgs.). Psicologia social dos valores humanos. São Paulo: Senac, 2006.

TAMAYO, A.; GONDIM, M. G. C. Escala de valores organizacionais. Revista de Administração, v. 3I, n. 2, p. 62-72, I996.

TAMAYO, A.; MENDES, A.; M.; PAZ, M. G. T. Inventário de valores organizacionais. Estudos de Psicologia, v. 5, n. 2, p. 289-315, 2000.

TAMAYO, A.; SCHWARTZ, S. H. Estrutura motivacional dos valores humanos. Psicologia: Teoria e Pesquisa, v. 9, n. 3, p. 329-348, I993.

VERGARA, S. C. Projetos e relatórios de pesquisa em administração. 3. ed. São Paulo: Atlas, 2000. 